\title{
Absorption of Stationary Elastic Vibrations in Rocks
}

\author{
E. V. KARUS
}

A quantitative interpretation of the tinamical characteristics of seismic waves in the Earth, revealed by the study of real media structure, is possible in cases, when the parameters of elastic waves attenuation in rocks are known. It is also important for a correct understanding of physical na- bration. The elastic power supplied by the coil-moved vibration equal to 50 watt. This vibrator is used to set up continuous vibrations at frequencies ranging from $40 \mathrm{c} / \mathrm{s}$ to $5.000 \mathrm{c} / \mathrm{s}$. It is known that stationary elastic vibrations comprise the superposition of compressional, shear and surface (Ray-

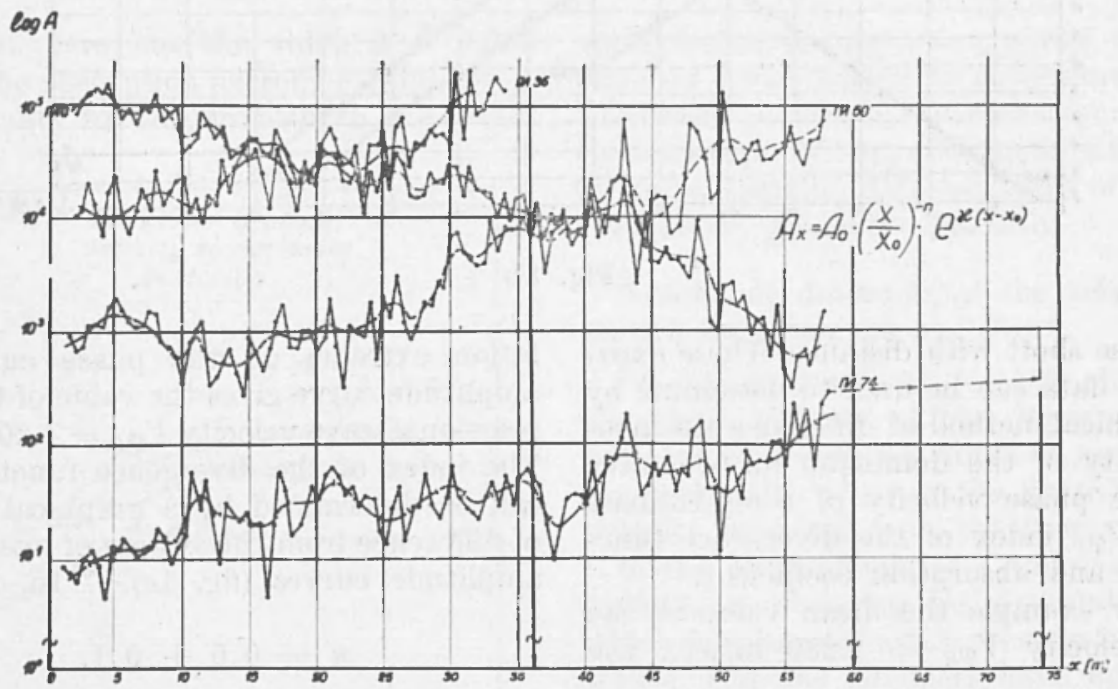

Fig. $1 \mathrm{a}$

ture of propagation of elastic waves and study of mechanical properties of rocks.

To measure parameters, characterizing divergence and absorption of seismic waves, the seismoacoustic method based on amplitude-and-phase measurement of elastic vibrations generated by a source of stationary harmonic vibration in rocks " in situ ": was used ( ${ }^{1}$ ).

For this purpose a special portable apparature was constructed. The elastic waves are generated by the electrodynamical vi- leigh) waves. [The dominant is the Rayleigh wave $\left.\left({ }^{2}\right)\right]$. These vibrations excited in the rock can be registered with maximum magnification about 20.000 .000 . To raise the effective sensitivity of the receiving device a special filtering system is used. The response characteristics make us enable to filtrate the signal within the frequency band of about $2 \mathrm{c} / \mathrm{s}$ for any frequency of excitation.

Fig. 1. gives an example of seismoacoustic observations in a mine at a depth of 250 metres. The observations were carried out 
in December of 1957 , in silvinite potassium salt. The profile is 75 metres long. The observations were conducted with the interval of 0.5 meter. This resulted in the creation of a system of reversed and overlapping amplitude (fig. 1a)-and-phase (fig. 1b) curves, graphs characterizing decrease of amplitude wavelength $\lambda=3 \mathrm{~m}$., the value of the phase velocity of the compressional wave determined by the formula:

$$
\frac{1}{V \varphi_{R}}-\frac{1}{V \varphi_{P}}- \pm \frac{1}{\delta x f},
$$

where $\delta x$ is the distance between the ondu-

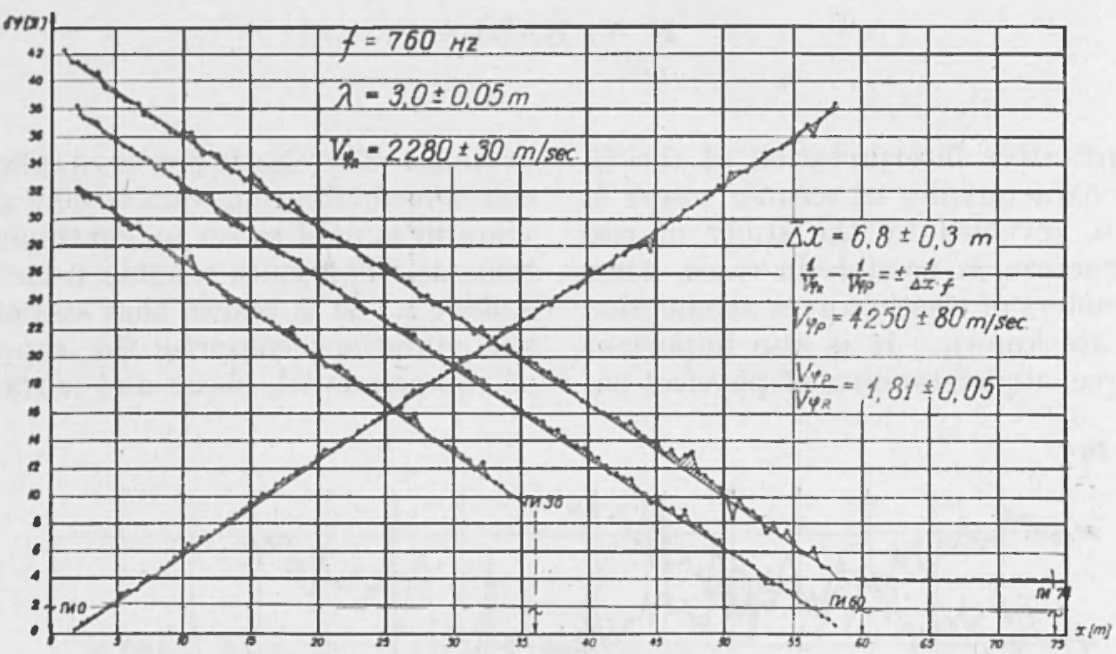

Fig. $1 \mathrm{~b}$

and phase shoft with distance. These experimental data can be used to determine by the graphical method of difference the phase velocity of the dominant surface wave $V_{p_{R}}$, the phase velocity of compressional waves, $V_{\varphi_{P}}$ index of the divergence function " $n$ " and absorption coefficient.

In our example the mean value of the phase velocity $V_{\varphi_{R}}=2.280 \mathrm{~m} / \mathrm{sec}$., the lation extrema on the phase curve and amplitude curve gives the value of the compressional wave velocity $V_{\varphi_{P}}=4.200 \mathrm{~m} / \mathrm{sec}$. The index of the divergence function " $n$ " can be determined by a graphical method of difference from the system of overlapping amplitude curves (fig. 1c). In our case

$$
n=0.5 \pm 0.1 \text {. }
$$

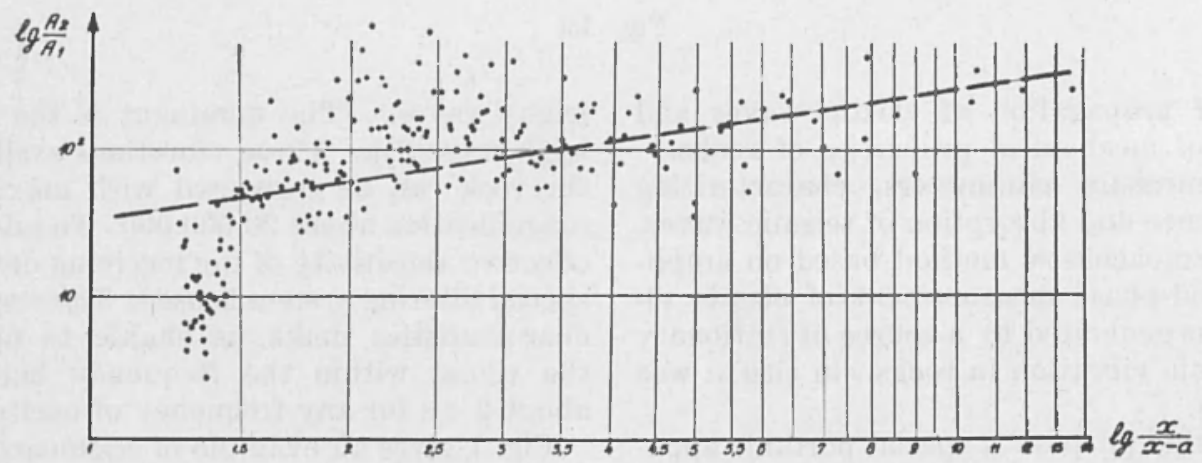

Fig. 1 c 
The absorption coefficient can be determined by a graphical way from system of reverse curves (fig. $1 d$ ). The absorption
These seismoacoustic parameters were determined in homogeneous rocks occurring near the Earth's surface, such as loess-like

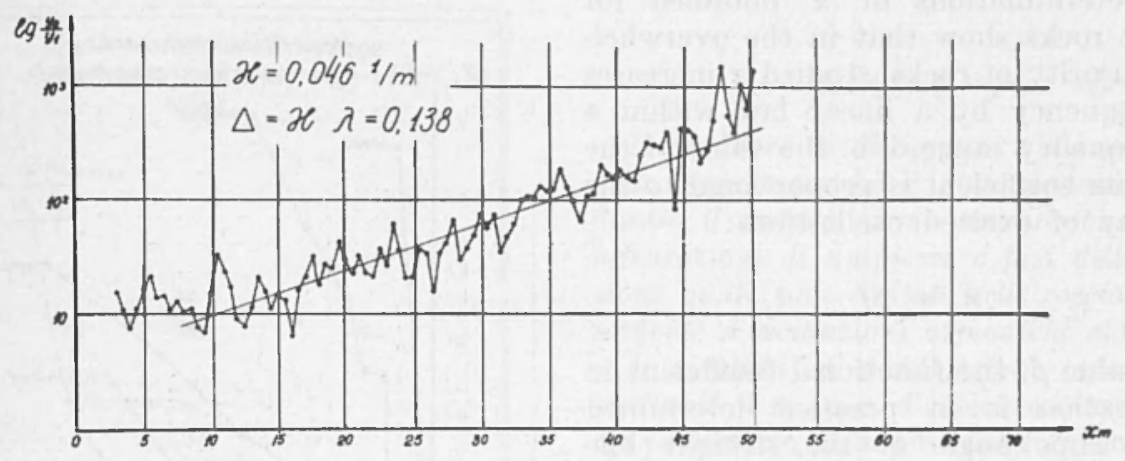

Fig. 1 d

coefficient here has the value $x=0.086$ $1 / \mathrm{m}$. The absorption decrement, the absorption quality for the wavelength $\Delta=\cdot 0.13$.

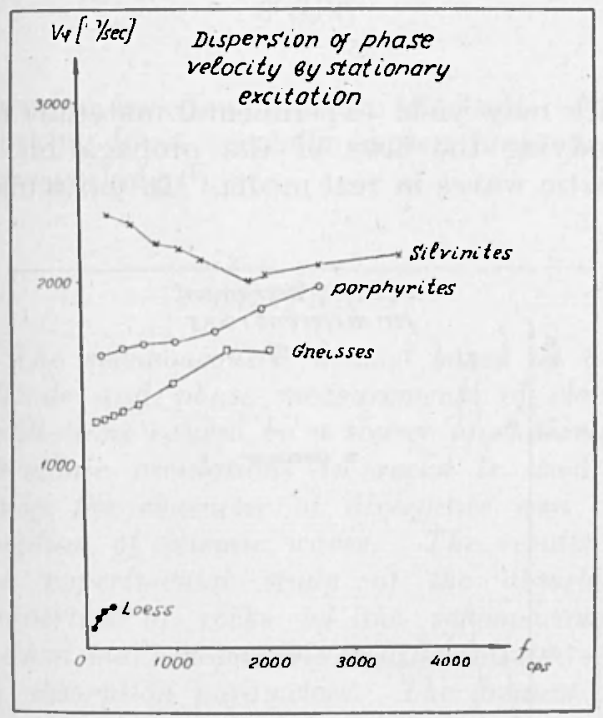

Fig. 2

The seismoacoustic method was used to measure the phase velocities, divergence indices, coefficients and decrements of the absorption of armonic elastic waves with frequencies ranging from 80 to $4.500 \mathrm{c} / \mathrm{s}$. sandy loams, porphyrites, gneisses. Observations in mines helped to determine seismoacoustical parameters of rocks occurring at depths of 150-270 m., such as: acmite cherts, silvinite, jaspilite, different kinds of iron ore (magnetite, gematite, martite).

Results of determining the seismoacoustical parameters are as follows:

1) On fig 2 we can see the chaning of the phase velocity of the dominant wave with the frequencv for different rocks. For the rocks wich occur at the Earth's surface velocity increases with the frequency rise, i. e. the phenomenon of "Anomalous" depression is observed for dominant waves which in seismoacoustics seem to be surface waves. But the silvinites have normal dispersion, i. e. the main plase velocity decreases with frequency.

2) The comparison of the given data on fig. 3 leads to the conclusion that it is possible to differentiate rocks by absorption of elastic waves. Great absorption is characteristic of loess-like sandy loams. Gneisses have greater absorption than porplyyritic rocks.

Metamorphycal rocks and silvinite occurring at depths of $150-220 \mathrm{n}$. are characterized by lesser values of $x$ and $\Delta$ than those occurring near the Earth's surface. Mine pressure and absence of decay pro- 
cesses stipulate more elasticity and lesser values of absorption parameters at a depth.

3) Determinations of $\%$ obtained for different rocks show that in the overwhelming majority of rocks studied $x$ increases with frequency by a linear law within a wide frequency range, i. e. the value of the absorption coefficient is proportional to the frequency of excited oscillations:

$$
x=\beta f
$$

The value $\beta$, the functional coefficient in this equation is in practice determined by the slope angle of the straight line approximating the graph of dependance of $\varkappa$ to $f$.

This table given the results of determining $\beta$ for different rocks.

Table 1

\begin{tabular}{|r|c|c|}
\hline Name of Rock & $\begin{array}{c}\text { Depth of } \\
\text { occurrence }\end{array}$ & $\beta$ (sec/n) $\times 10^{4}$ \\
\cline { 2 - 2 } Gneisses . & 0 & 3.1 \\
Porphyrites . & 0 & 1.2 \\
Martitic ore. & 262 & 2.0 \\
Jaspilites . . & 212 & 1.0 \\
Silvinites . . & 247 & 0.6 \\
Magnetito-he- & 267 & 0.2 \\
matitic ore & 267 & 0.4 \\
Acmite cherts & 267 \\
\hline
\end{tabular}

4) The values of the absorption decrement $\Delta$ of a rock differ, though the sensible law of change of $\Delta$ with frequency is observed (fig. 4). This can be seem from the demonstrated diagram where changes with frequency are plotted for: gneisses, porphyrites, silvinite. The correlation of average values of phase velocity $V p_{R}$ and absorption decrement $\Delta$ for diflerent rocks shows (fig. 5) that rocks possessing a greater absorption coefficient are characterized by a low phase velocity, i. e. inverse proportionality is observed between $\Delta$ and $V_{\varphi_{R}}$.
In conclusion we want to say, that a thorough investigation of absorbing properties of rocks with the help of seismoacou-

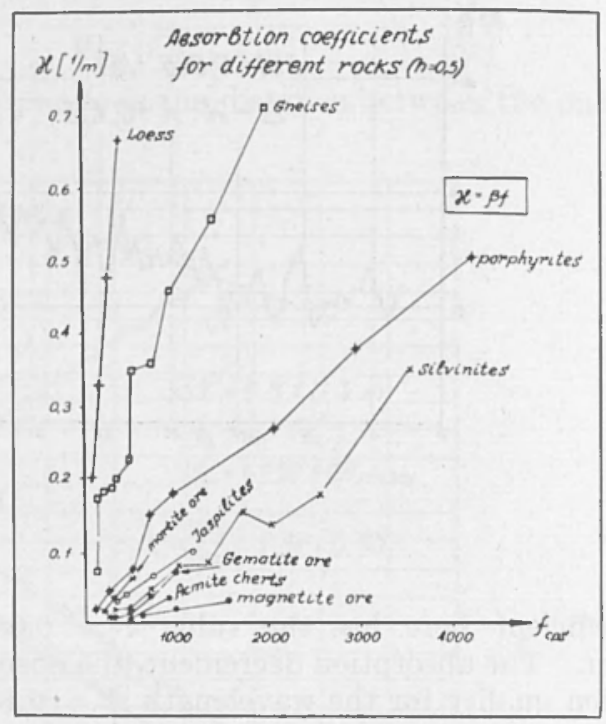

Fig. 3

stics may yield experimental materials for studying the laws of the propagation of elastic waves in real media. In particular,

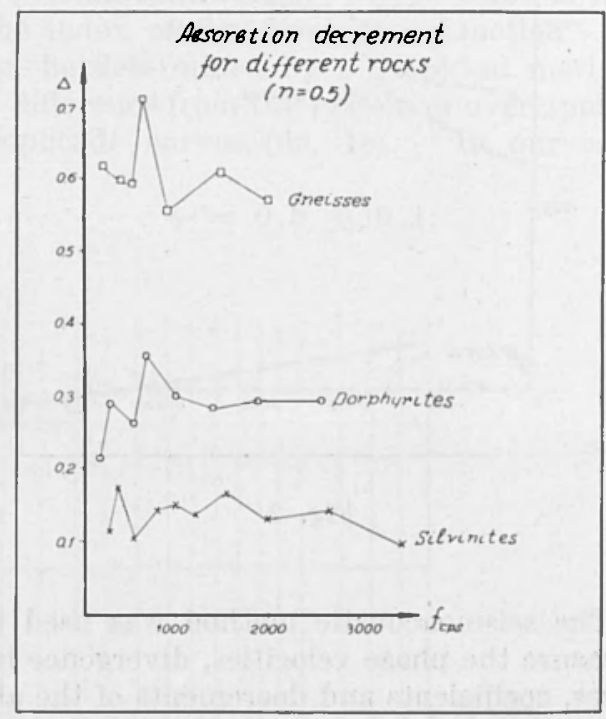

Fig. 4 
the data obtained by us confirm the conclusion made by B. V. Deryagin who has explained the nature of seismic wave ab-

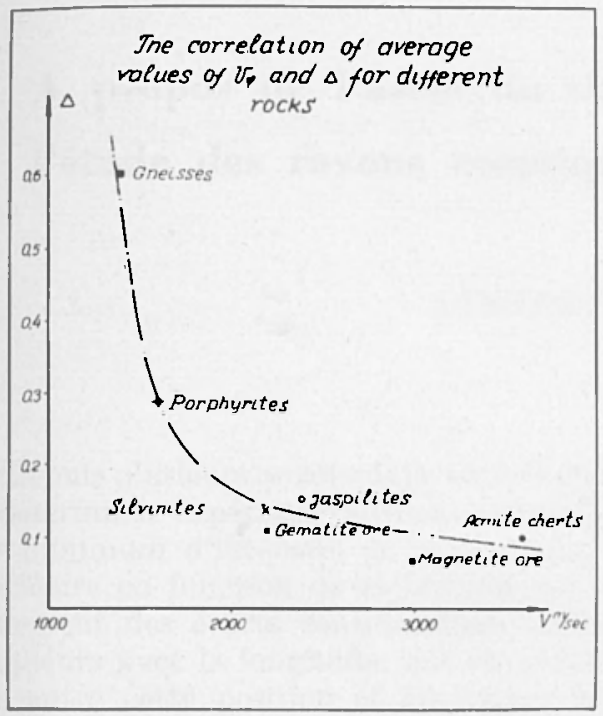

Fig. 5

sorption based on the use of elastic afterworking for a specially chosen function of afterworking ( $\left.{ }^{4}\right)$.

\section{ABSTRACT}

The seismoacoustic method based on amplitude and phase measurements of elastic oscillations caused by a source of stationary harmonic oscillations in rocks is used to study the character of divergence and $a b$ sorption of seismic waves. The results of the experimental study of the absorbing properties of rocks by the seismoacoustic method make it possible to differentiate rocks by absorption parameters. The greatest $a b$ sorption is acquired by sedimentary rocks, the least - by erupted and metamorphized rocks. Inverse dependance between the velocity of elastic waves and absorption decrement has been observed for different types of rocks. It was shown that for the prevailing majority of the rocks investigated the $a b$ sorption coefficient increased with frequency under the linear law.
It is pointed out that the experimental data obtained confirm the conclusions made from the theory developed by B. V. Derjagin based on the phenomenon of the elastic after-effect.

\section{RIASSUNTO}

Il carattere di divergenze e d'assorbimento delle onde sismiche $\dot{e}$ stato investigato mediante il metodo sismo-acustico basato sulle misurazioni di ampiezze e fasi delle oscillazioni quali sono eccitate nelle roccia da una sorgente d'oscillazioni armoniche stazionarie.

I risultati d'investigazione sperimentale mediante il m. s.-a. d'assorbimento della roccia permettono di differenziare le roccie diverse secondo i parametri d'assorbimento. L'assorbimento massimo è proprio di roccia sedimentaria il minimo di roccia d'eruzione e di roccia sottoposta a un metamorfismo.

La proporzionalità inversa è stata osservata tra la velocità delle onde elastiche e la diminuzione d'assorbimento per $i$ tipi diversi di roccia. $\grave{E}$ dimostrato che il coefficiente d'assorbimento è aumentato linearmente con la frequenza. $\grave{E}$ osservato il fenomeno della dispersione anomala della velocità di fase.

I dati sperimentali ottenuti confermano le conclusioni della teoria basata sul fenomeno d'elasticità in seguito a quella svolta da B. V. Derjagin.

\section{B I B L I O G R A F I A}

(1) Karus, E. V., Pasechnik, I. P., Methods of studying elastic and absorbing properties of rocks in their natural occurrence by the methods of seismoacoustics, Izvestia, Ac. Sc. USSR. geophys. ser., 6 (1954).

${ }^{2}{ }^{2}-1$ - On the nature of the elastic waves excited in real media by a harmonic source, Izvestia Ac. Sc. USSR, geopliys. ser., 2 (1955).

$\left.{ }^{3}\right)$ - Albsorption of elastic waves in rocks by stationary excitation. Izvestia Ac. Sc. US SR, geoplıys. ser., 4 (1958).

(4) Derjagin, B. V., Damping of seismic and acoustic waves and its independence on frequency. "Journal of Geopliysies ", 3.4 (1931). 